\title{
SITUATIONAL AWARENESS WINDOWS FOR DISASTER MANAGEMENT - A SYSTEMS APPROACH USING DSM AND AHP
}

\author{
Navneet Bhushan \\ Crafitti Consulting Private Limited, \\ Bangalore, INDIA \\ E-mail: navneet.bhushan@,crafitti.com
}

\begin{abstract}
The rapidly globalizing world is creating complexities that demand unprecedented capabilities from decision-makers who find themselves in the middle of situations that can lead to disasters rapidly. These situations are called crises and/or disasters. These situations are characterized by extremely intertwined interplay of many factors in a volume of time and space. Decision-makers need capabilities to understand the interplay of these factors in time and space, comprehension of their meaning, and rapid projection of their interplay in near future to be able to comprehend and potentially conceive courses of action that lead to robust mitigation of crisis/disaster or managing the impact of crisis/disaster if the events have occurred. These capabilities have been termed as situational awareness (SA). A comprehensive SA is important in all decision making scenarios, however, it is critical in case of disaster and crisis situations as the disaster (man-made or natural) by definition lead to extreme loss for the affected community. Combining the 9 windows or 9 screens or system operator from the methodology of TRIZ (Russian acronym translated as Theory of Inventive Problem Solving), Dependency Structure Matrix (DSM) with the Analytic Hierarchy Process (AHP), this paper describes a comprehensive framework for SA called SAWS (Situational Awareness WindowS). The paper also provides a case study with an application to disaster management for bio-war situation that is the most likely weapons of mass destruction (WMD) that non-state actors may use in their attempt to terrorize.
\end{abstract}

Keywords: 9 windows, DSM, Crisis Management, AHP, TRIZ, Weapons of Mass Destruction (WMD), Bio War 
ISAHP Article: Bhushan/Situational Awareness Windows for Disaster Management - A systems approach using DSM and AHP To Be Submitted to the International Symposium of the Analytic Hierarchy Process 2014, Washington D.C., U.S.A.

\section{Introduction}

How efficiently any crisis or disaster is handled depends upon the decision-making capabilities and resources available. At the organizational level there is a need to have a strategic situation awareness framework for decision making. A crisis and disaster management framework as described in [Bhushan and Rai, 2004] defines three stages of disaster management namely - crisis avoidance, crisis management and disaster management. Various factors impacting these three stages in general are also described and a framework using Analytic Hierarchy Process (AHP) is also described. This paper combines the AHP framework for disaster management with the concept of nine windows or system operator from the theory of inventive problem solving (Russian problem solving methodology TRIZ) and Dependency Structure Matrix (DSM) to describe a new strategic situational awareness framework named Situational Awareness Windows (SAWS). DSM helps in clustering various factors impacting the situation in nine windows. This extended abstract describes the key components of the framework applied to the context of bio-terrorism disasters.

\section{System Operator from TRIZ}

The theory of inventive problem solving (TRIZ) is a problem solving methodology developed on the basis of analysis of thousands of patents. (See http:/www.trizjournal.com and http://aitriz.org). A concept in TRIZ called nine windows or system operator is a simple means of thinking in TIME and SPACE. The basic principle of operation divides 'the world' into nine segments. In SAWS we map the central window of the 9 windows to crisis avoidance on the time axis and "system" - which in the case study on bioterrorism below is the nation or country. (See http://www.trizjournal.com/archives/2001/09/c/index.htm for more information on nine windows).

\section{Bio-Terrorism Disasters}

The gravest threat the world is facing today is the probability of low intensity conflicts being suddenly transformed into a high intensity conflict through possession, threat of usage and actual use of weapons of mass destruction (WMDs) by actors (state and nonstate actors) that are resorting to low intensity conflicts against nation states. The most dangerous and most likely way a covert actor will resort of an act of war or terrorism is by possessing, threatening to use and actual usage of Biological weapons - although chemical and nuclear weapons cannot be ignored. Use of biological agents to create mass casualties against a nation state this will have a dramatic impact. Covert actor's decision to use biological weapons has sound logic as it is relatively easy to remain covert with bio weapons. Further, one needs small quantities as the living organisms used as bio weapons for example, multiple themselves, are relatively cheap and easy to produce, very 
ISAHP Article: Bhushan/Situational Awareness Windows for Disaster Management - A systems approach using DSM and AHP To Be Submitted to the International Symposium of the Analytic Hierarchy Process 2014, Washington D.C., U.S.A.

difficult to detect and potentially available. Further, biological agents do not have to be pure to create casualties - the very fact of usage has a massive psychological impact.

\section{Situation Awareness Windows Framework for managing Bio-terrorism disasters}

Situation Awareness Windows Framework for managing Bio-terrorism disasters

As per the system operator or nine windows we divide the space dimension into Supersystem as the world at large, System as the country or nation subjected to bio-attack and sub-system as the specific city or cities in the nation state that are likely to be attacked. The framework asks the experts for various factors that will impact the nine windows of SAWS and then rank order them using the well-established methodology of AHP. Figure below describes the output of the SAWS when all factors in nine windows are rank ordered using AHP.

\section{Key References}

Bhushan, N., \& Rai, K (2004). Strategic Decision Making - Applying the Analytic Hierarchy Process, Springer, UK. 